\title{
Embracing the "Foggy Place" of Theatre History: The Chautauqua/Colloquia Model of Public Scholarship as Performance
}

\author{
Jane Barnette
}

In her December 2013 Slate polemic “The End of the College Essay: An Essay," Rebecca Schuman calls for the end of assigning and grading papers in required courses. Since "the baccalaureate is the new high-school diploma" and "students (and their parents) view college as professional training," professors should "declare unconditional defeat" and abandon the dated notion that writing essays is a necessary part of a decent undergraduate education. ${ }^{1}$ As a theatre historian with training in rhetoric and composition, I have incorporated numerous student-centered writing strategies in theatre history, literature, and theory courses, but ultimately I have taken a similar stance when discussing departmental curricula with my colleagues: I question the value of traditional (that is, reader-oriented and paper-based) research/writing assignments within the major.

For those of us who teach "book" courses for theatre majors, a frequent obstacle we face is that our classes do not offer opportunities for public performance and therefore (to many students, as well as colleagues) the value of what we teach can be invisible. ${ }^{2}$ When the department curriculum includes history/theory courses, they are often upper-division classes with substantial writing components, exacerbating the divide between practice-oriented curricula and the scholarly coursework required for theatre majors. However, at the root of this assumed divide is a limited and limiting notion of writing that is at odds with theatrically savvy students and teachers: in this divide, students write for readers, and teachers grade papers. At both Kennesaw State University (KSU) and the University of Kansas (KU) I piloted an entirely different approach wherein students wrote for performance, and I graded presentations.

In other words, at the root of the question I pose here (and I suspect Schuman's indignation) is a frustration with the disconnection between traditional academic writing and critical thinking. Several recent studies indicate the decline of attentive reading in the age of digital skimming and bemoan the 140-character limits of the Twitter generation's prose; some of this research suggests that students are losing the ability to write as the basis of critical thinking. ${ }^{3}$ On the flip side, the evidence culled from the Stanford Study of Writing has provided an alternate narrative: that twenty-first-century students are writing more than ever before, but that they prefer "self-sponsored" writing, or writing for/as performance. To quote one of the students involved with this study, Beth McGregor: "For me, the force of the embodied performance is unparalleled by the written word" (Fishman et al. 238). Especially within a program based on live performance, the assumption that reader-based prose is the best way to assess theatre studies seems obviously misplaced. As students advance in scholarship, writing papers for reading audiences becomes a valuable undertaking, and for most graduate students this traditional approach still has merit; but for today's undergraduate theatre majors, if we want to engage their intellectual curiosity (and preserve our own sanity) we must approach scholarship as a public performance. 
This approach is anything but new-it harkens back to the ancient world with its emphasis on oratory-but it is more locally grounded in the American tradition of Chautauqua presentations, and thus I call my theatre history research/writing project the "Chautauqua/Colloquium." Over the past decade I have held these events at least once each semester, and each time I did so I learned from my mistakes and successes and continued to refine the project. In what follows, I will provide an overview of the historical and pedagogical rationale for oral/aural learning, followed by a summary of the specific assignment and its process, and ending with an analysis of the assessment data from both faculty and students. In so doing, I hope to demonstrate the ways in which the oral performance of scholarship can enhance the effectiveness and enjoyment of the scholarly theatre classroom.

\section{The Chautauqua Approach/Tradition}

The definition of the word Chautauqua remains a matter of some debate, since the word derives from American Indian (specifically Seneca) usage. Geographically speaking, Chautauqua Lake in New York State (where the cultural phenomenon has its roots) certainly looks like the definition frequently embraced today, "a bag tied in the middle." But other Seneca translations include "the place where one is lost" and "the foggy place." The Kansas Historical Society (in its description of Kansas's Chautauqua County) has chosen to adopt the latter of these, "foggy place," and I find this to be the most evocative definition of the event I use to teach research and writing.

More than a place, however, the Chautauqua tradition was a movement rooted in the American Methodist tradition of moral "uplift" for rural adults. Beginning in 1874 and becoming a thriving business model by the early twentieth century, the Chautauqua movement sought to educate rural Americans by offering patriotic music, recitations of poetry and Shakespeare, and elocutionary speeches by virtuosos the likes of William Jennings Bryan, Charles Dickens, and Mark Twain. Once a year (typically during the summer), adults from the hinterlands of the country would gather under a tent to listen to and catch a glimpse of these speakers. The power of such community bonding was not lost on US politicians, especially during the throes of the Great War, when participants recited the "Good Citizen's Creed": "As a good citizen I believe it is my duty to my country to LOVE it; to obey its laws, to respect its flag, and to defend it against all enemies." In this way (among others), the Chautauqua tradition became "the most American thing in America," as Teddy Roosevelt celebrated it. ${ }^{4}$

In addition to moral uplift, Chautauqua presentations also provided opportunities to witness performance during a period and within regions that otherwise shunned theatre. As both Charlotte Canning and John Gentile demonstrate, solo performances by "readers" (a euphemism for actors) were often the highlight of Chautauqua events for attendees. The most common text for performance was Shakespeare, although others "read" literature and poetry, and these readings were considered a kind of educational entertainment.

By the dawn of radio broadcasting in 1920 interest in Chautauqua performances began to wane, in part because the touring phenomenon became so widespread that the local specificity was no longer a draw, but also because the reach of radio supplanted the demand for entertainment and conversation that Chautauqua presentations had provided. Later in the twentieth century, however, interest in the Chautauqua model was revived as part of the ongoing Chautauqua Institution hosted near the aforementioned lake in New York State.

While the religious roots of the Chautauqua tradition may seem at odds with secular classrooms, the way that it encourages community bonding through the mutual delight of education is not. Ultimately, the reason I chose the Chautauqua model stemmed from my desire to ignite a culture of scholarship as performance among theatre undergraduates who take theatre history courses. The 
nature of the assignment itself helped make this possible, while the framework of the Chautauqua model inspired the crucial shift from reader-based to listener-based prose.

The Chautauqua model also connects multiple strands of conversations within the scholarship of teaching and learning, many of which are within the subfield of postsecondary composition pedagogy, particularly at the crossroads of writing and performance. Inspired by the Stanford Study of Writing and the analysis it made possible, during the last decade several scholars have suggested that students benefit when performance and writing are combined. ${ }^{6}$ In 2007 the Conference on College Composition and Communication (CCCC) recognized the need to reframe how higher education views writing by issuing its "Statement on the Multiple Uses of Writing," which acknowledged that "writing instruction [was] being called upon to multiply its vision and . . . move outward from its traditional emphasis on academic contexts and forms to include public, cross-cultural, professional, personal, and artistic contexts and forms." Included among the genres of writing it affirms in this white paper are oral presentations, debates, dialogues, correspondence, and scripts. Composition scholars' recognition of performance-based writing is both innovative and historically rooted, as noted by Jenn Fishman and colleagues, who reassert performing bodies as "ghosts in the writing machine." They reference rhetorician Kenneth Burke, who sought to "restore to rhetoric its own longstanding tradition of performance, which centers on interconnections between language and live performance or delivery" (228). Theatre-based scholars of teaching and learning have offered further insight into what Fishman et al. call the "irrepressible" performance aspect of writing, within the context of a range of courses, most of which have had significant writing components. ${ }^{\text {? }}$

In particular, Shelley Manis and Ryan Claycomb provide insight into the ways that performance-based pedagogy has been central to their approaches to teaching composition. Manis shares key assertions that I have made here when she insists that "we must engage the voice and the body as well as the written word" (141). Her examples of how to employ this approach in theatre history classrooms also align with my project, insofar as they emphasize counterarguments and debate, as well as paraphrasing and scrutinizing scholarly texts—both central to this research/writing assignment that culminates in a Chautauqua/Colloquium presentation. While Manis applies writing-as-performance (and performance-as-writing) to her theatre history classroom, Claycomb culls his insight primarily from a rhetoric and composition course. He suggests "eight different notions of performance that already do and/or potentially could infuse our work in the writing classroom: Performance as metric; Performance as action; Performance as audience-focused; Performance as theatre; Performance as embodiment; Performance as ritual; Performance as role; and Performance as Heisenberg's principle.” Each of these aspects of performance is relevant to my project and its potential for reframing how writing gets taught within theatre departments, but of the eight listed by Claycomb, it is the final one- the way performance calls to mind Heisenberg's principle- that matters most, for it summons the vulnerability and radical agency crucial to both theatre and writing.

The uncertainty evoked by Heisenberg's principle—-that we cannot "catch" an electron in the act, that we cannot observe particles without changing their behavior-is familiar territory for performance scholars and practitioners. Having an audience changes the dynamic onstage and each spectator will offer different feedback, but none of them will see the exact same performance. As Claycomb argues, "with its ephemeral ability to disappear as it is happening and its essential difference from its own artifacts, [performance] is particularly resistant to discursive control—we cannot censor that which has already happened; what we discipline . . . is only ever a trace of that performance." 8 In similar ways, as I will detail in the following section, the Chautauqua/Colloquium project embraces the "foggy place" of both the process and product of research by challenging what many students perceive to be the objective nature of scholarship (namely, because it is published it must be fact) and encouraging them to join the conversation as young scholars themselves. Along the way (much like in rehearsals and performance itself), they must embrace failure. As Sara Jane Bailes claims in the context of contemporary performance, but I suggest equally applies to this 
kind of pedagogy, "[a]s a trope or mode of activity, failure is inclusive, permissive even. . . F Failure works" (2; emphasis in original). By purposefully designing a research assignment that encourages the "foggy place" of the kind of breakdown that Bailes describes, students embody the uncertainty of writing and performance.

They do so through several assignments of increasing value, from "low-stakes" to "highstakes," throughout the term. In each of these assignments, in keeping with the principles of both good writing and good theatre, the audience for hearing the student's developing argument changes. The focus throughout each step remains on oral/aural composition, with attention to "real-world" skills (for example, business letters and public speaking), as well as the opportunity to culminate this project in "writing that is self-performed," all of which serve to make this approach to researchbased writing matter.?

\section{Overview of Chautauqua/Colloquium Project}

The assignment at the heart of this project requires students to pinpoint a scholarly disagreement over a matter of history/theory interpretation. ${ }^{10}$ For undergraduate students to follow the trail of a particular conversation in academic writing they have to abandon their typical approaches for research: they cannot use research to "prove" a predetermined thesis, nor can they choose their topic without first conducting a basic search. Without question, this is the most challenging aspect of the assignment; no matter how many ways I might try to explain the difficulty or distinctive qualities of this type of research, most students must discover through failure what the assignment requires. The fact that this project requires virtually every student to fail early on in the process is one of its strengths: because the failure occurs early it helps to discourage procrastination, and through peer assignments the students bond over their shared frustration and eventual triumphs.

To help illustrate this point, as I review these stages, I will reference two hypothetical students, Amy and Carl, composites representing typical A and C students as they might encounter this assignment. As will become evident, both Amy (the A student) and Carl (the C student) find the project challenging, and at some point in the process will consider their work (or even themselves) a failure; however, by the end of the project they will gain confidence, critical thinking skills, and improve their persuasive writing.

Much like a production for the stage, public scholarship should go through the rigors of a thorough rehearsal process. With my eye on the dates for presentation I create room in my syllabus for the equivalent writing stages for the following rehearsal stages: dramaturgy and table-work (the research proposal), blocking (the outline), and cue-to-cue tech work (script consultations). These three sections of the project are also assignments, with increasing point value (see table 1). In addition to these parts of the assignment I also incorporate peer work in the second two phases (the outline and presentation), for a total of 10 percent of the final grade devoted to peer feedback.

\section{Dramaturgy and Table-work}

The project begins with the research proposal, which includes two parts: the debate question, and the annotated bibliography. To complete this first step, the student must conduct the necessary research, which can often take several hours. Because I require that they pinpoint a disagreement among or between scholars, the first challenge for students is to ascertain the writer's argument and the specific contribution it claims to make to the field. This is surprisingly difficult for undergraduate readers, who often assume that if an article is published it must be "fact" rather than the "foggy place"; one of the advantages of this debate-centered assignment is the way in which it reinforces the basic problem of history, or the necessity of conjecture in all historical interpretation. Over the years 
Table 1. Writing Stages of the Chautauqua/Colloquium Theatre History Research Project

\begin{tabular}{lcccc}
\multicolumn{1}{c}{$\begin{array}{c}\text { THEATRE- } \\
\text { MAKING Process }\end{array}$} & $\begin{array}{c}\text { Dramaturgy } \\
\text { and table-work }\end{array}$ & $\begin{array}{c}\text { Directing and } \\
\text { designing }\end{array}$ & $\begin{array}{c}\text { Tech } \\
\text { week }\end{array}$ & Performance \\
$\begin{array}{l}\text { Equivalent stage } \\
\text { of C/C project }\end{array}$ & Research proposal & Outline & Consultations & Presentation \\
$\begin{array}{l}\text { Percentage of final } \\
\text { course grade }\end{array}$ & 5 & 10 & Attendance taken & 15 \\
$\begin{array}{l}\text { Audience feedback } \\
\text { Instructor }\end{array}$ & Peer and instructor & Instructor & $\begin{array}{c}\text { Peer, public, } \\
\text { and instructor }\end{array}$ \\
\hline
\end{tabular}

I have noticed several strategies that can help struggling students in this first phase: first, I suggest that they consider articles written before and after 1968. Thanks to the influences of deconstruction and the attention to gender and minorities that the civil rights movement helped make possible, scholars writing before and after this watershed year often interpret events and evidence differently. Second, I draw their attention to the margins of the essays themselves: the notes and the bibliography. Frequently, undergraduates see manuals of style as rule books with no real purpose, but through this assignment they might glimpse how and why citation methods help scholars communicate. Since this part of the process is like detective work, students with advanced citation knowledge emerge as valuable resources in the class, and those who can connect the notes to the bibliography have distinct advantages over those who cannot. Finally, I teach them how to scan and search an article before reading it for meaning. I circulate a list of useful research tools for the project, directing them to databases like Project Muse, JSTOR, and Academic Search Complete. On the day I introduce the project I invite the class to brainstorm the sorts of words that a scholar might use to indicate disagreement; the resulting list (usually including words like however, although, and so on) becomes a resource for them during this phase. We also discuss the importance of reading the introduction and conclusion before investing in the entire article; if they cannot pinpoint the argument by using these tools, then I encourage them to move on.

Some students enter this phase with a false confidence, based on previous success writing papers from a thesis-driven research mode. These students are accustomed to doing research that supports their assertion and are likely unfamiliar with the process of tracking academic discourse. Amy, for example, begins her project with the assertion that Greek women did, in fact, attend the City Dionysia. She assembles her proposal using the research tools I suggest, but overlooking the goal of the assignment: to find debate. Instead, she reads the material with such a focused eye on her desired result that she misinterprets the scholarship entirely, missing the subtleties of academic prose that qualify or even negate the argument she believes she has found. In other words, she looks in the right places, but uses the wrong approach; like many writers, she searches for scholarship that supports her thesis rather than allowing the scholarship to guide her into the conversation. Carl, on the other hand, is likely stumped on how even to begin. He may know that he enjoys commedia dell'arte and feels strongly that he wants to write about the masks used for this genre, but quickly discovers that the tools I have suggested yield few (if any) results in locating a disagreement within scholarship about this topic. Instead, Carl finds descriptive histories of commedia dell'arte, or perhaps even disagreements about where (or how) the form began.

Both Amy and Carl can still earn an "A" on the first assignment, however, if they demonstrate that they have done due diligence in attempting to find a debate by listing their research in proper MLA format (a requirement for this stage), in a fully annotated bibliography, with a debate question in bold. Although both students might have to fudge their question, since neither has a viable topic for this project yet, I make it clear that I grade the first stage on following directions and effort, 
not the fortunes of discovery. What I look for here is an opportunity to intervene: with Amy, for example, I would suggest that she read Sue-Ellen Case's take on the misogyny of Greek theatre; for Carl, I would attempt to steer him to another topic entirely, since most debates about commedia dell'arte boil down to questions of origin, which tend to be reductive.

After the students turn in this first assignment I typically have about half of the class ready to move forward, while the other half needs to start their research anew. It is crucial at this stage to identify which students have viable proposals; to do so I often have to scan and search the articles myself, since frequently students misunderstand the subtlety of the arguments. However, it is impossible to catch all of the errors in this first phase; the second step is designed to help identify those students whose proposals seemed plausible, but are not based on the scholarship itself.

\section{Directing and Designing}

The second step is ostensibly an outline, but since the presentation format itself is rather formulaic, this stage is truly a stopgap measure to catch the problematic research that was not evident on the first pass. Because every student is required to present both sides of a scholarly disagreement, the format of the papers typically follows an arrangement of summarizing each scholar's perspective before the students offer their own conclusions. Even so, most students struggle with the outline phase-it demonstrates their unfamiliarity with academic prose, as well as their resistance to outline writing in general, but it also reveals frequent misunderstandings between what the authors wrote and what the student (often passionately) believes they meant. In order to tease out these disconnections, I require that students include at least two quotations from each scholar cited in the outline, and I ask them to resubmit their annotated bibliography (which typically needs revision).

At this stage, the differences in Amy's and Carl's quotations will reflect their levels of engagement with the texts. It is likely that Amy finds excerpts from her scholars that successfully illustrate how they disagree about the portrayal of gender onstage in ancient Greece, but the scholarly verbiage she quotes is not yet ready for public presentation. Carl might have more difficulty in parsing scholars' arguments from their descriptions (especially if his sources are not appropriate for the assignment) and will need to return to the research to either find better quotations or better sources.

I address these difficulties by devoting a day early in the term to work in class on the outlines; this workshop allows students to revise their work based on the feedback they receive. It is these revisions that their peers critique. In order to ensure that students actually attend and participate in this crucial workshop (even if their work is under-prepared), I have to emphasize the in-progress nature of the outline, and stress that the outline (however rough) is their ticket in the door. Even so, virtually every semester at least one student shows up without an outline in hand, so I continue to refine my strategies. The process I have developed will work for everyone who has completed his or her research (and has their bibliographies and selected quotations in hand).

The writing workshop has two parts: the first solo work, the second in peer pairs. For the first section, I distribute unlined paper and ask them to close their eyes and listen to the following paragraph of descriptive prose: "This small room contains several pieces of well-polished wood furniture. Eight ornate, high-backed chairs surround a long oval table, and a side table stands next to the far exit. All bear delicate carvings of various shapes. One bears carvings of skulls and bones, another is carved with shields and magic circles, and a third is carved with shapes like flames and lightning strokes." After hearing this I ask them to sketch the table described. I give them a few minutes of frustration and then reread the passage, encouraging them to take notes as they listen. They are not to consult with one another during this phase, but to work individually. After about ten minutes of sketching I have them mingle with one another in order to find a peer whose sketch is most like theirs. Once they have found their best match they show me the drawings and find a seat together. 
Although students often predict that I am using this warm-up exercise to discover who their best peer will be for the main workshop, this is not my goal; instead, I want to generate a discussion about the differences between listener-based and reader-based prose. "How would the sketch have been different if you had been given the paragraph to read?" I ask. "What differences were there between the way you heard the description and the way your peers heard the description? Why did you pick your peer?" The conversation that ensues allows for several revelations to occur, most of which boil down to the crucial observation that writing (like performance) relies entirely upon audience reception. If the overall goal is not yet clear to them I finish this first section by asking: "Why would I ask you to sketch a table when we're working on our outlines?" To further emphasize the link between this activity and their assignment I play a video of a student presentation at a previous Chautauqua/Colloquium event, and then we discuss when the student excelled at listener versus reader-based prose.

This sets the scene for how to proceed with the outline in class, in peer pairs. I assign the pairs based on the subject matter, grouping similar research interests together so that if the peers have sources that can help each other, they can share them. Following with the emphasis on listening rather than reading, I ask the peers to exchange outlines and then for each student to pitch their research question orally to their partner. At this point the partners are encouraged to take notes, with attention to where the speaker deviates from the outline and how the spoken prose may simplify (or complicate) the question. Because they are not allowed to look at their own outline while giving this pitch, this step brings to light just how familiar students are with their research. If they have been working steadily on the project this will be easy for them; if they have procrastinated it will show. After hearing the pitch the partners parrot back what they heard, allowing the writer to hear for herself what the question sounds like in speech.

Following the exchange of pitches the writers receive their outlines back and read aloud the quotations they have included. This allows the partners to provide feedback about the length and scope of the chosen quotation, and redirects writers to choose (or edit) scholarly prose for oral presentation. Based on the feedback they have received students return to their outlines and revise them for submission a week later, to both their peer and me.

Upon receipt of the polished outline the peers write a letter to me about their partner's progress from the class workshop to the revision. This letter, formatted as a business letter, addresses several questions I pose in the peer assignment, but also allows students to refine their writing for the formal prose expected in professional correspondence, a skill they will need for cover letters upon graduation. By reading this letter alongside the revised outline, I get a better sense of which students fully understand the nature of this assignment (for example, that it is focused on scholarship and not on their own hypotheses) and which students have discovered a viable topic. For those who have not, I require individual consultations at this stage so that I can redirect them to known (often previously presented) debates in the field.

This rehearsal phase functions much like any performance's rehearsals might; there are discoveries, both negative and positive, which result in changes in direction, repetition of processes, additional discoveries, and ultimately selection. For most students, researching in this way is antithetical to how they have been taught to write college essays thus far and consequently are uncomfortable in the "foggy place" they must occupy for the Chautauqua/Colloquium assignment. However, if they fight against the discomfort and read carefully, they can discover aspects of theatre history that their instructor may not yet know; in my particular case, each semester that I teach theatre history my approach alters according to the discoveries made by previous students engaged with this project.

The next phase of the research project is the writing of the script, which I have set as a nonnegotiable deadline, required for participation in the final presentations. That said, the script itself is not graded. Indeed, I do not read the script; instead, I set aside at least one class day for scheduled 
individual consultations of thirty minutes each, during which time I have the students read their scripts aloud to me before offering feedback. ${ }^{11}$ One of the benefits of this approach is that in the act of reading aloud their writing, students often discover for themselves where the syntax of their scripts falls short and what needs revision.

\section{Tech Week}

Thus begins the tech-rehearsal phase of the Chautauqua/Colloquium project wherein I help the students refine the timing, enunciation, and projection of their public scholarship. Over the course of several additional rehearsals we create a five-to-six-minute oral presentation that has maximum impact. Although I call it "Tech Week," this part of the process usually lasts two weeks, or at least a week and a half, with one of the days roughly equivalent (for the instructor) to a "10 out of 12" technical rehearsal. ${ }^{12}$ These are the days that I schedule the required individual rehearsals for each student, and I have them read through their script in front of a music stand, as they will on the day(s) of their presentation. I time these speeches and require that students bring two paper copies to the rehearsals so that I can write comments on one script while they read the other. After they have spoken through the text once, we review my notes, ranging from comments on active verbs or how to parse down a difficult quotation from a scholar to which words to emphasize. Often, I will require a follow-up meeting to rehearse further, especially if the script needs significant revision and most of my focus was on verbiage rather than style.

For example, Carl might come to the first tech rehearsal with a script that does not include sufficient quotations, while Amy's script might rely too heavily upon her scholars' words. I recommend a balance of $80 / 20$ for the presentation, wherein 80 percent of the script is either paraphrase or resulting opinion and 20 percent is direct quotation. ${ }^{13}$ Students are not required to memorize the script; rather, they are expected to make eye contact with audience members, meaning that they must become quite familiar with the wording, and they must also indicate the beginning and ends of quotations by stating (something like) "quote" and "unquote" throughout.

Significantly, this is also the phase wherein students refine or develop their conclusions for the speech. Unlike other assignments (especially in theatre classrooms) where the focus of the paper is often their opinion or argument, most of their focus for this project has been on the scholarship. They have been researching and writing about (at least) two scholars who disagree about a topic in theatre history - a shift away from not only their own voice, but also from the topic itself. Amy, for example, might begin by writing a script that includes several paragraphs of exposition or explanation about ancient Greece, gender roles, and so on. But this is not the assignment. She must shift her focus away from the topic (how was femininity portrayed onstage in ancient Greece?) so that she can focus on the scholarship (who disagrees with whom, and why, based on what evidence?). However, in the conclusion Amy returns to more familiar writing skills—evaluative rhetoric.

Conclusions are crucial to any argument, yet most college students are taught to equate concluding statements with summative or even repetitive sentences. Instead, I urge students to consider relevancy and historiography in their conclusions - the "so what?" query, with a historiographic twist. For example, perhaps Carl discovers that one of his scholars published their essay while still a graduate student, while his other scholar is a distinguished professor. What does this different status mean to him, and why? Further, perhaps one of his scholars uses ephemeral evidence-letters, say, found in an archive-while another uses literary analysis. How do these different approaches toward evidence influence his opinion about which scholar presented the best case? While most students will be tempted to fall into the "both-scholars-have-merit" trap, I insist that they take a stance in the conclusion, even if it means that they disagree with both (or all) scholars and suggest an alternate reading of the evidence in question. 


\section{Opening Night}

The excitement leading up to the event is somewhat akin to opening night for a production, especially after establishing the Chautauqua/Colloquium as a tradition within the department. By the time I left KSU it was not uncommon to have a "full house" for these presentations and see alumni of the program return as spectators. At KU attendance among faculty and graduate students was strong, although so far there have been few undergraduate student spectators who were not part of the class.

It is this stage, the performance itself, that solidifies the value of the assignment for theatre history pedagogy. Not only does the performance give purpose to the writing, but it makes the bonding experience of communitas possible. The ritual of the Chautauqua/Colloquium, especially in the context of KSU, where it was required as part of the major in theatre and performance studies, is a rite of passage, a liminal phase "betwixt and between" enrollment and graduation-or, more crucially, a solidifying of the hybrid ideal of scholar-artist. ${ }^{14}$ To perform one's scholarship is to fully embrace this hybridity, and in the group experience of watching others perform and being part of a panel oneself, one becomes part of something more than a classroom experience: one joins the community of scholar-artists.

For students who prefer behind-the-scenes work, especially design/technology and stage management, to acting, opening night understandably conjures stage fright. I can imagine Amy as a stage manager who dreads public speaking, while Carl might assume that his natural charisma as a stand-up comic will charm the audience, even if his research is less persuasive. That said, our rehearsals make these anxieties manageable; indeed, often the most successful presentations are given by students who struggle most with initial stage fright, in part because their attentiveness to the earlier parts of the process is necessarily more intense. It is for this reason that the assessment format is weighted toward critical thinking and persuasive argumentation over presentation style or delivery.

\section{Reviews}

There are three primary avenues for audience feedback on the Chautauqua/Colloquium presentations: discussion/questions, peer evaluation, and instructor assessment. Between each group of presentations (structured much like a micro-version of the typical academic conference panel) I moderate audience discussion and questions for the panelists, with an explicit discouragement of evaluative comments. For example, Amy might be asked a question about sexuality following her presentation on the performance of gender, while Carl's topic may inspire a heated discussion about the value of primary versus secondary evidence. Often, a topic of discussion that emerges is the prevalence of presentism - the human tendency to interpret or evaluate evidence using the meanings or values of one's own time period rather than those of the era of study. ${ }^{15}$ It is difficult, for instance, for students to fully comprehend that sexual identity is a relatively recent historical construction, one that is not shared across cultures currently and was nonexistent for millennia.

Each student is also assigned another student to evaluate; this peer is different from the peer assigned during the outline phase (to ensure that most students are evaluating a peer presenting on a day or at a time different from when they are presenting themselves). The rubric used for the peer evaluation directly mirrors the one I use as instructor: of the total point value for the project, only 30 percent comes from how the material is presented; the remaining 70 percent corresponds to the content and persuasiveness of the speech, such as how well it was introduced and concluded, how precise the speaker was about quoting scholars, and how thoroughly the speaker considered concessions and refutations or the devil's advocate position in the presentation. ${ }^{16}$

After the presentations are done, there is another round of reviews to consider: namely, how the event is remembered by the participants and spectators. At KU, where I introduced the project 
in 2014, one student reflected on the experience as follows: "I found this entire project awesome. I was nervous and hesitant at first with the amount of work I had to do. By the end, I was happy and confident about my work. I also learned a vast amount of theatrical history I otherwise would not have had the chance to." While this perspective was not shared by all students, it shines a light on the possibility of how the Chautauqua/Colloquium approach to teaching theatre history can address the acknowledged desire among college students to embody writing and render it purposeful. ${ }^{17}$ With ample evidence to support writing for/as performance, those of us who teach theatre and performance studies are especially equipped to find innovative and inspiring approaches to the writing components of our courses. By presenting student scholarship publicly and regularly, we help develop a culture of performance that includes theatre history not just as a requirement, but an equal player.

\section{Acknowledgments}

I would like to acknowledge the support (both financial and intellectual) that the Center for Excellence in Teaching and Learning (CETL) at KSU afforded me, as well as the diligence that my graduate teaching assistant, Danny Devlin, provided in my first semester at KU. Without the CETL staff, Devlin, and, most crucially, the courage of my students and colleagues at both institutions, this project would not have been possible.

Jane Barnette is a theatre historian and freelance dramaturg who writes about adaptation, train culture, and American pageantry. A recipient of the Distinguished Teaching Award for the College of the Arts at Kennesaw State University, she was one of twelve professors named as a Georgia Governor's Teaching Fellow in 2012. She is currently an assistant professor in the Department of Theatre at the University of Kansas, and is completing a book on adaptation dramaturgy for the Theater in the Americas series of Southern Illinois University Press.

\section{Notes}

1. Schuman's polemic hit a nerve. In a blog post titled "Behold, my Second-Most Controversial Article Ever," she enumerates the ways in which her article has been misinterpreted, and crystallizes her satiric/darkly humorous take on the academy. The vitriol of responses to Schuman rose to such a level that digital humanities scholar Adeline Koh penned "An Open Letter in Defense of Rebecca Schuman" for The Chronicle of Higher Education soon thereafter.

2. By "book" courses, I refer colloquially to theatre studies classes (for example, theatre history, theory and/ or literature, and script analysis), rather than the practice-oriented classes (acting, design, directing, voice, movement).

3. One example of this line of thinking is the 2012 debate sponsored by Atlantic, spearheaded by an article ("The Writing Revolution" by Peg Tyre) published therein, provocatively titled "Why American Students Can't Write."

4. See Charlotte Canning, The Most American Thing in America: Circuit Chautauqua as Performance (2005).

5. Charlotte Canning, "The Platform versus the Stage: The Circuit Chautauqua's Antitheatrical Theatre" (1998); John Gentile, Cast of One: One-Person Shows from the Chautauqua Platform to the Broadway Stage (1989).

6. See Jenn Fishman et al., "Performing Writing, Performing Literacy” (2005).

7. Ibid. There are others besides the two theatre-based scholars, Shelley Manis and Ryan Claycomb, upon whom I focus here, many of them cited by the former in note 1 on page 149 , and others who have published 
or presented since then. While an exhaustive review of this literature exceeds the scope of this essay, I do want to draw attention to the recent work of Mark Carnes, Nancy Kindelan, and Scott Magelssen.

8. Claycomb, "Performing/Teaching/Writing: Performance Studies in the Composition Classroom" (n.p.).

9. This notion of "self-performing" was central to one of the students involved in the Stanford Study of Writing cited above, Mark Otuteye; see Fishman et al., "Performing Writing, Performing Literacy,” 238.

10. I adapted this research assignment from one that Jack Brokaw used at the University of Texas at Austin.

11. Class size is crucial to the success of this project, as one might suspect from the frequency of out-of-class meetings. At KSU I had between fifteen and twenty students in each theatre history class (a luxury that I recognize many readers do not share); at KU, however, the class had thirty students, and I modified the project to accommodate this size by selecting half of the students to present live and requiring the other half to submit unlisted YouTube videos of their presentations. My graduate teaching assistant, Danny Devlin, also consulted with and provided project feedback to students, thus dividing my workload in half, although extra time was devoted to mentoring him through the consultation process. While the process is time-consuming, I much prefer the in-person consultations to grading papers in the traditional way.

12. A "10 of 12" is a common part of "tech week" for theatre rehearsals. It refers to the ten hours that the cast and crew work in a twelve-hour day.

13. The $80 / 20$ divide is based on my experience and stems from my desire to hear more of the students' words and help them develop the skill of paraphrasing. For more on the importance of this skill, see Manis, "Writing as Performance" (2009).

14. For more on communitas and liminality, see Victor Turner, "Liminal to Liminoid in Play, Flow, and Ritual."

15. I am grateful to John Gentile for his introduction of presentism into KSU Chautauqua/Colloquium conversations.

16. This percentage roughly corresponds to how the field views the assessment of oral communication and writing, as evidenced by the VALUE Rubrics for each (oral communication and writing), provided by the Association of American Colleges and Universities (AAC\&U). It is worth noting that the AAC\&U considers the assessment of writing separate from that of oral communication, yet several of the categories in the latter (organization, language, supporting material, and central message- four of the five, where the fifth is delivery) correlate with the former. See the AAC\&U's website, available at <www.aacu.org/value-rubrics>.

17. This feedback was received through a postmortem exercise in which I asked students to reflect on what was positive, as well as negative, about the Chautauqua/Colloquium at KU. While the quoted student did not include a negative (saying "it was all great"), others certainly did. For example: "I HATED doing the research" and "This was the most stressful project I've ever worked on." That said, the course instructor's evaluations for this same course were excellent, as were the evaluations for my history/theory sequence at KSU, indicating that overall, students felt challenged by though ultimately grateful for the experience.

\section{Works Cited}

Bailes, Sara Jane. Performance Theatre and the Poetics of Failure: Forced Entertainment, Goat Island, Elevator Repair Service. London: Routledge, 2011.

Canning, Charlotte. "The Platform versus the Stage: The Circuit Chautauqua's Antitheatrical Theatre." Theatre Journal 50.3 (1998): 303-18. 
. The Most American Thing in America: Circuit Chautauqua as Performance. Iowa City: U of Iowa P, 2005.

Carnes, Mark C. Minds on Fire: How Role-Immersion Games Transform College. Cambridge, MA: Harvard UP, 2014.

Claycomb, Ryan. "Performing/Teaching/Writing: Performance Studies in the Composition Classroom." Enculturation 6.1 (2008), available at <http://enculturation.net/6.1/claycomb>.

Conference on College Composition and Communication (CCCC). "Statement on the Multiple Uses of Writing." Position statement, November 2007, available at <www.ncte.org/cccc/resources/positions/ multipleuseswriting>.

Fishman, Jenn, Andrea Lunsford, Beth McGregor, and Mark Otuteye. "Performing Writing, Performing Literacy." College Composition and Communication 57.2 (2005): 224-53.

Gentile, John. Cast of One: One-Person Shows from the Chautauqua Platform to the Broadway Stage. Champaign: U of Illinois P, 1989.

Kindelan, Nancy. Artistic Literacy: Theatre Studies and a Contemporary Liberal Education. New York: Palgrave Macmillan, 2012.

Koh, Adeline. "An Open Letter in Defense of Rebecca Schuman." ProfHacker (blog), The Chronicle of Higher Education, 17 December 2013, available at <http://chronicle.com/blogs/profhacker/an-openletter-in-defense-of-rebecca-schuman/54301>.

Magelssen, Scott. Simming: Participatory Performance and the Making of Meaning. Ann Arbor: U of Michigan P, 2014.

Manis, Shelley. "Writing as Performance: Using Performance Theory to Teach Writing in Theatre Classrooms." Theatre Topics 19.2 (2009): 139-51.

Schuman, Rebecca. "The End of the College Essay: An Essay.” Slate.com, 13 December 2013, available at $<$ http://www.slate.com/articles/life/education/2013/12/college_papers_students_hate_writing_them_ professors_hate_grading_them_let.html>.

. "Behold, my Second-Most Controversial Article Ever." Pan Kisses Kafka (blog), 13 December 2013, available at <http://pankisseskafka.com/2013/12/13/behold-my-second-most-controversialarticle-ever/>.

Turner, Victor. "Liminal to Liminoid in Play, Flow, and Ritual." From Ritual to Theatre: The Human Seriousness of Play. New York: PAJ, 1982. 20-60.

Tyre, Peg. "The Writing Revolution.” Atlantic.com, October 2012, available at <http://www.theatlantic. com/magazine/archive/2012/10/the-writing-revolution/309090/>. 